\title{
Preparation of continuous alumina gel fibres by aqueous sol-gel process
}

\author{
HONGBIN TAN*, XIAOLING MA and MINGXING FU \\ School of Materials Science and Engineering, Shaanxi University of Technology, Hanzhong Shaanxi 723 003, P. R. China
}

MS received 26 April 2010; revised 26 June 2012

\begin{abstract}
Continuous alumina gel fibres were prepared by sol-gel method. The spinning sol was prepared by mixing aluminum nitrate, lactic acid and polyvinylpyrrolidone with a mass ratio of 10:3:1.5. Thermogravimetrydifferential scanning calorimetry (TG-DSC), Fourier transform infrared (FTIR) spectra, X-ray diffraction (XRD), and scanning electron microscopy (SEM) were used to characterize the properties of the gel and ceramic fibres. The $\mathrm{Al}_{2} \mathrm{O}_{3}$ fibres with a uniform diameter can be obtained by sintering gel fibres at $1200{ }^{\circ} \mathrm{C}$.
\end{abstract}

Keywords. Continuous gel fibre; sol-gel method; $\mathrm{Al}_{2} \mathrm{O}_{3}$; polyvinylpyrrolidone.

\section{Introduction}

Alumina is one of the most important materials because of its high strength and modulus, resistance to attacks from molten metals and non-oxide materials, chemical inertness in both oxidizing and reducing atmospheres up to $1000{ }^{\circ} \mathrm{C}$, and good electrical insulation (Venkatesh and Ramanan 2002; Zhu et al 2008). It also has high melting point $\left(T_{\mathrm{m}}>2040{ }^{\circ} \mathrm{C}\right)$ and low thermal conductivity $\left(10^{-18} \mathrm{~W} / \mathrm{m} \cdot \mathrm{K}\right.$ ) (Sedaghat et al 2006). An important potential application of alumina is as fibre reinforcement of metals, ceramics and resins.

Main processes for the manufacture of ceramic fibres can be classified as melt-spinning process and sol-gel spinning process (Zhang et al 2009). Usually, the melt-spinning method is adopted for the synthesis of ceramic fibres with low melting point. Thus, this method is not suitable for the preparation of the alumina fibres.

The preparation of short alumina fibres has been widely reported (Poulon-Quintin et al 2004; Chandradass and Balasubramanian 2006; Maneeratana and Sigmund 2008; Shojaie-Bahaabad et al 2008). Chandradass and Balasubramanian (2006) prepared alumina short fibres by sol-gel process using aluminum-tri-isopropoxide as starting materials, and Shojaie-Bahaabad et al (2008) synthesized composite fibres ( $\mathrm{YAG} / \mathrm{Al}_{2} \mathrm{O}_{3}$ ) from an aqueous solution of aluminum powder, aluminum chloride hexahydrate and yttrium oxide by the sol-gel method. But, the preparation processes of continuous gel fibres have not observed in the relevant reports.

In the present work, continuous alumina gel fibres were prepared by sol-gel method using aluminum nitrate (AN) and lactic acid (LA) as raw materials and polyvinylpyrrolidone (PVP) as a spinning additive. The process, phase

\footnotetext{
*Author for correspondence (hb-t@ 163.com)
}

crystallization and surface morphology were investigated in detail.

\section{Experimental}

\subsection{Preparation of samples}

Starting materials used were AN (Chemically grade, Xi'an reagent factory, Xi'an, China), LA (Chemically grade, Xi' an reagent factory, Xi'an, China) and PVP (Chemically grade, Sinopharm Chemical Reagent Co. Ltd., Shanghai, China).

Alumina fibres are prepared in the processing steps as shown in figure 1 . The aluminum lactate $(\mathrm{AL})$ gel was prepared by mixing $\mathrm{H}_{2} \mathrm{O}$, aluminum nitrate and lactic acid, followed by being heated in a water bath at $80{ }^{\circ} \mathrm{C}$. The proper amount of water and spinning additive (PVP) were added in the AL gel, and then the precursor sol was concentrated to obtain a spinning sol in the water bath $\left(60^{\circ} \mathrm{C}\right)$. Gel fibres were prepared by pulling a thin glass rod slowly from the sol after immersing, and dried at $60^{\circ} \mathrm{C}$ for $24 \mathrm{~h}$ in an oven. The gel fibres were then sintered at 800,1000 and $1200{ }^{\circ} \mathrm{C}$ for $1 \mathrm{~h}$, respectively, with a heating rate of $1{ }^{\circ} \mathrm{C} / \mathrm{min}$.

\subsection{Characterization techniques}

Thermal behaviours of the gel fibres were measured by TG/DSC instruments (SDT Q600, TA Instrument, American) with a heating rate of $10{ }^{\circ} \mathrm{C} / \mathrm{min}$ in the flowing $\mathrm{N}_{2}$, and Fourier transform infrared (FTIR) spectrum was recorded on an infrared spectrometer (6700, Nicolet Magna, American) with the samples as $\mathrm{KBr}$ pellets. X-ray diffraction analysis was carried out on an X-ray diffractometer $(\mathrm{D} / \max 2400$, Rigaku, Japan) using $\mathrm{CuK}_{\alpha}$ radiation with a step of $0.05 \%$ s. Morphologies of heat-treatment fibres were characterized by scanning electron microscopy (SEM, S-2700, Hitachi, Japan). All tests were done at room temperature. 


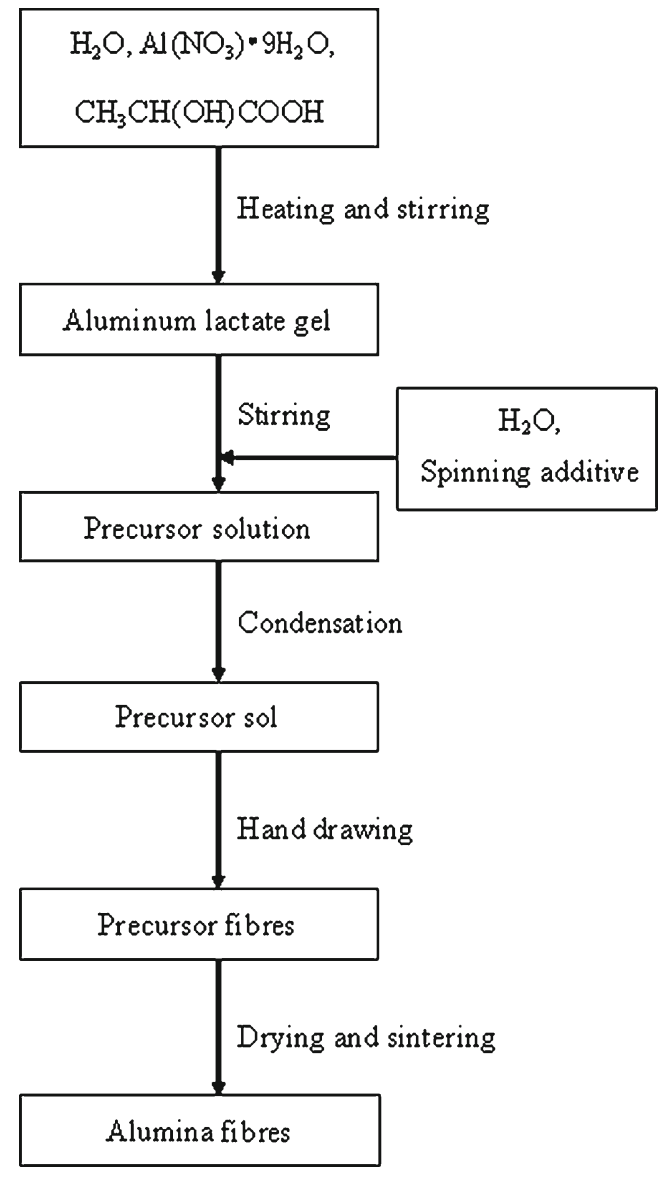

Figure 1. Schematic view of production route for alumina fibres.

\section{Results and discussion}

Aluminum lactate was prepared after the reaction took place between aluminum nitrate and lactic acid in an aqueous solution during the stirring and heating. The main chemical reactions may be simplified as the following equation, although the actual reactions were complex:

$$
\begin{aligned}
& 3 \mathrm{CH}_{3} \mathrm{CH}(\mathrm{OH}) \mathrm{COOH}+\mathrm{Al}\left(\mathrm{NO}_{3}\right)_{3} \\
& \quad \rightarrow \mathrm{Al}\left[\mathrm{CH}_{3} \mathrm{CH}(\mathrm{OH}) \mathrm{COO}\right]_{3}+3 \mathrm{HNO}_{3}, \\
& \mathrm{HNO}_{3} \rightarrow 1 / 2 \mathrm{H}_{2} \mathrm{O}+1 / 4 \mathrm{O}_{2} \uparrow+\mathrm{NO}_{2} \uparrow .
\end{aligned}
$$

The spinnability of different precursor sols estimated from the length of the gel fibres drawn from the spinnable condensed sols, is shown in table 1 using different amounts of lactic acid or spinning additive. The spinnability of the sol is determined by the content of lactic acid or spinning additive. For example, when the lactic acid amounted to $6 \mathrm{ml}$ in the sol 1, the sol is spinnable because most of aluminum nitrate is involved in the reaction to generate aluminum lactate. The hydrolysis and condensation polycondensation can occur when the aluminum lactate solution is condensed, and a spinnable sol with the linear molecular chains is obtained after a concentrating process in a water bath at $60{ }^{\circ} \mathrm{C}$. The
Table 1. Effect of the LA or PVP on the spinnability of precursor sols.

\begin{tabular}{lcclc}
\hline No. & AN (g) & LA $(\mathrm{g})$ & PVP $(\mathrm{g})$ & Spinnability $(\mathrm{cm})$ \\
\hline 1 & 10 & 3 & 0 & 0 \\
2 & 10 & 6 & 0 & 40 \\
3 & 10 & 3 & $0 \cdot 5$ & 10 \\
4 & 10 & 3 & $1 \cdot 0$ & 60 \\
5 & 10 & 3 & 1.5 & $>100$ \\
\hline
\end{tabular}

AN: aluminum nitrate, LA: lactic acid, PVP: polyvinylpyrrolidone. A mass ratio of AN and distilled water was 1:5. The spinnability of the alumina sol is estimated from the length of the sol fibres drawn from the spinnable condensed sols.

main reaction can be simplified as the following (Zhang and Eckert 2004; Apelblat et al 2005; Zhang et al 2007):

Hydrolysis:
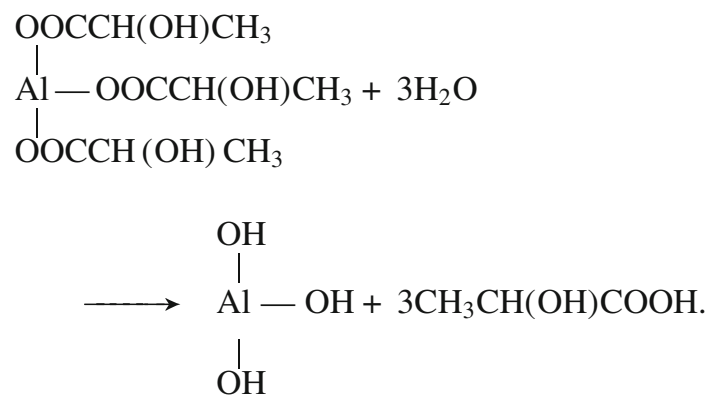

Condensation polymerization:

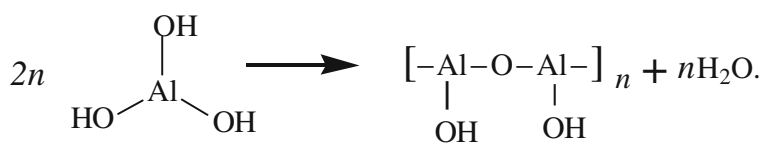

Otherwise, if too much organic acid remains, the densification of alumina ceramic fibres will be delayed during calcinations because aluminum lactate has a high decomposition temperature (Venkatesh and Ramanan 2000; Leivo et al 2009). When the content of PVP increases, the spinnability also increases in sol $3-5$. Sol 5 is suitable for fibre preparation because long fibres could be obtained.

TG/DSC curves of the precursor gel fibres are shown in figure 2 with a heating rate of $10{ }^{\circ} \mathrm{C} / \mathrm{min}$. DSC curve of the gel fibres exhibits three endothermic peaks at about 145,220 and $370{ }^{\circ} \mathrm{C}$, and two exothermic peaks at about 780 and $900{ }^{\circ} \mathrm{C}$. The endothermic peaks are assigned to evaporation of the adsorbed water, loss of the structure water and decomposition of hydroxides in the gel fibres, whereas the two exothermal peaks are assigned to the amorphous $/ \gamma-\mathrm{Al}_{2} \mathrm{O}_{3}$ transformation and $\alpha-\mathrm{Al}_{2} \mathrm{O}_{3}$ phase 


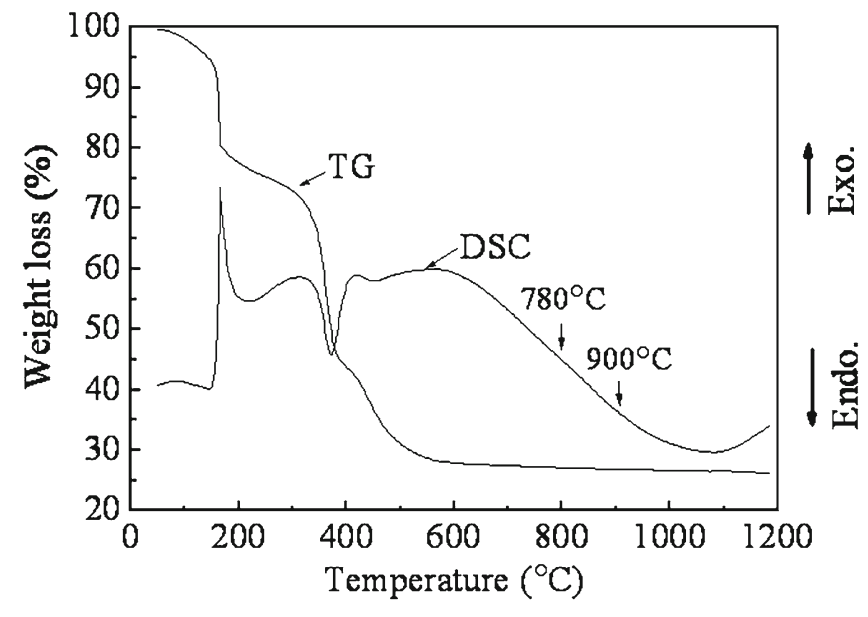

Figure 2. TG and DSC curves of alumina precursor gel fibres.

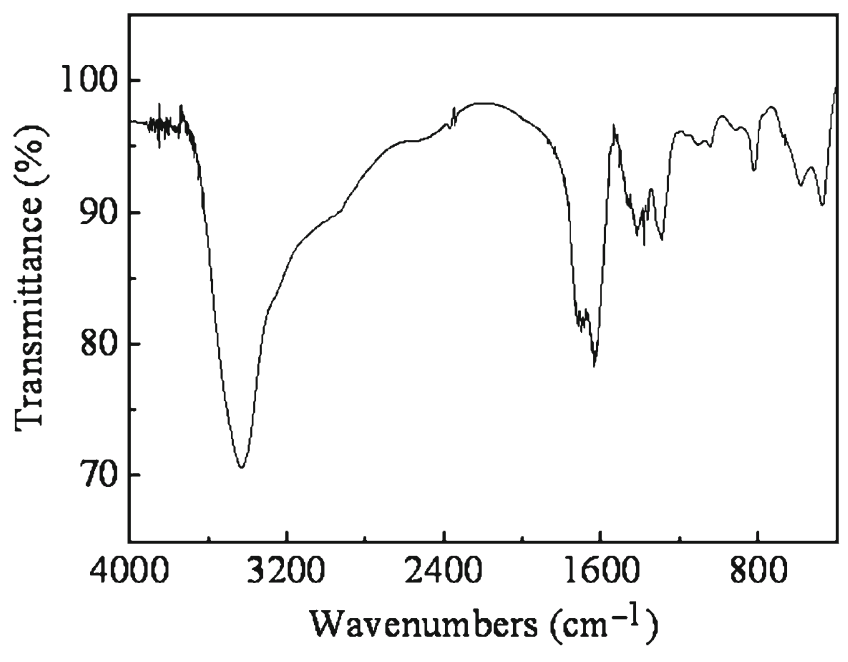

Figure 3. FT-IR spectrum of precursor gel fibres.

crystallization, respectively ( $\mathrm{Li}$ et al 2006). TG curve of the gel fibres shows a weight loss around $72 \mathrm{wt} \%$ at $600{ }^{\circ} \mathrm{C}$, while no further weight loss is observed above $600^{\circ} \mathrm{C}$.

FTIR spectrum of precursor gel fibres is shown in figure 3 . As can be seen, the bands at 3440 and $1116 \mathrm{~cm}^{-1}$ are assigned to the $\mathrm{O}-\mathrm{H}$ stretching modes and bending modes of adhesive and constitution water as well as lactic acid, respectively. The band at $2550 \mathrm{~cm}^{-1}$ is assigned to the $\mathrm{O}-\mathrm{N}$ stretching mode of nitric acid. The bands at 1710 and $476 \mathrm{~cm}^{-1}$ are assigned to the $\mathrm{C}=\mathrm{O}$ stretching modes and bending modes, respectively. The band at $920 \mathrm{~cm}^{-1}$ is assigned to the $\mathrm{C}-\mathrm{C}$ stretching mode. The bands at 1300 and $820 \mathrm{~cm}^{-1}$ may be assigned to the $\mathrm{C}-\mathrm{O}$ stretching modes and bending modes, respectively. As can be seen, a little of nitric acid and some lactic acid is present in the samples.

As shown in figure 3 , the band observed at $1420 \mathrm{~cm}^{-1}$ corresponds to $\mathrm{Al}-\mathrm{OH}$ bonding mode (Chandradass and Balasubramanian 2006). The stretching modes of Al-O-Al linkages are observed at 620 and $820 \mathrm{~cm}^{-1}$ (Padmaj et al

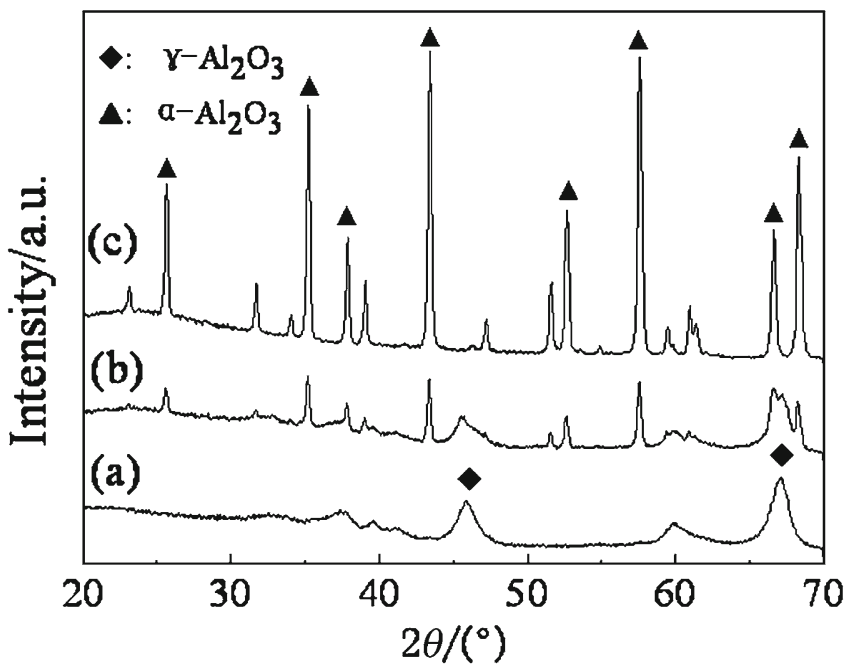

Figure 4. XRD patterns of alumina precursor gel fibres heated at (a) 800 , (b) 1000 , and (c) $1200{ }^{\circ} \mathrm{C}$ for $1 \mathrm{~h}$.

2001). When precursor solution is condensed, hydrolysis and condensation polycondensation can occur. So, the stretching modes of Al-O-Al linkages are observed.

The X-ray diffraction patterns of gel fibres sintered at 800 , 1000 and $1200{ }^{\circ} \mathrm{C}$ are shown in figure 4. Only amorphous and $\gamma-\mathrm{Al}_{2} \mathrm{O}_{3}$ phase are present when fibres are sintered at $800{ }^{\circ} \mathrm{C} . \alpha-\mathrm{Al}_{2} \mathrm{O}_{3}$ phase is observed in the samples sintered at $1000{ }^{\circ} \mathrm{C}$, while main $\alpha-\mathrm{Al}_{2} \mathrm{O}_{3}$ phase at $1200{ }^{\circ} \mathrm{C}$. From the DSC and XRD results, it can be concluded that $\alpha-\mathrm{Al}_{2} \mathrm{O}_{3}$ phase crystallization of the fibres occurs at about $900{ }^{\circ} \mathrm{C}$ shown in the DSC curves in figure 2.

It has been shown that the phase developments during crystallization of amorphous alumina takes place through the following route (Venkatesh and Ramanan 2002)

$$
\text { Amorphous } \rightarrow(\eta) \rightarrow(\gamma) \rightarrow(\delta) \rightarrow(\theta) \rightarrow(\alpha) .
$$

During heating, the $\theta-\mathrm{Al}_{2} \mathrm{O}_{3}$ undergoes a reconstructive transformation by nucleation and growth, where the oxygen atoms rearrange into a hexagonal close-packed structure to form thermodynamically stable $\alpha-\mathrm{Al}_{2} \mathrm{O}_{3}$ (Nordahl and Messing 1998). During the reconstructive transformation from $\theta$ to $\alpha$ alumina, there is a specific volume reduction $\left(28.6-25.6 \mathrm{~cm}^{3} / \mathrm{mol} \mathrm{Al}_{2} \mathrm{O}_{3}\right)$ due to the difference of theoretical density (3.6-3.986 g/ $/ \mathrm{cm}^{3} \mathrm{Al}_{2} \mathrm{O}_{3}$ ) (Nordahl and Messing 2002). A low intrinsic nucleation density results in large spacing between nucleation events and the formation of micrometer-scale, single crystal $\alpha-\mathrm{Al}_{2} \mathrm{O}_{3}$ grains with dendritic protrusions surrounded by continuous pore channels (Nordahl and Messing 2002). The resultant vermicular microstructure requires the sintering temperature greater than $1600^{\circ} \mathrm{C}$ to obtain high densities ( $\mathrm{Li}$ and Sun 2000). The sintering temperature can be decreased by adding low melting point phase (e.g. $\mathrm{SiO}_{2}, \mathrm{~B}_{2} \mathrm{O}_{3}, \mathrm{TiO}_{2}$ ) (Minnesota Mining and Manufacturing Company 1977).

SEM micrographs of alumina fibres sintered at $1200{ }^{\circ} \mathrm{C}$ are shown in figure 5 . The fibres have diameter of about 10 

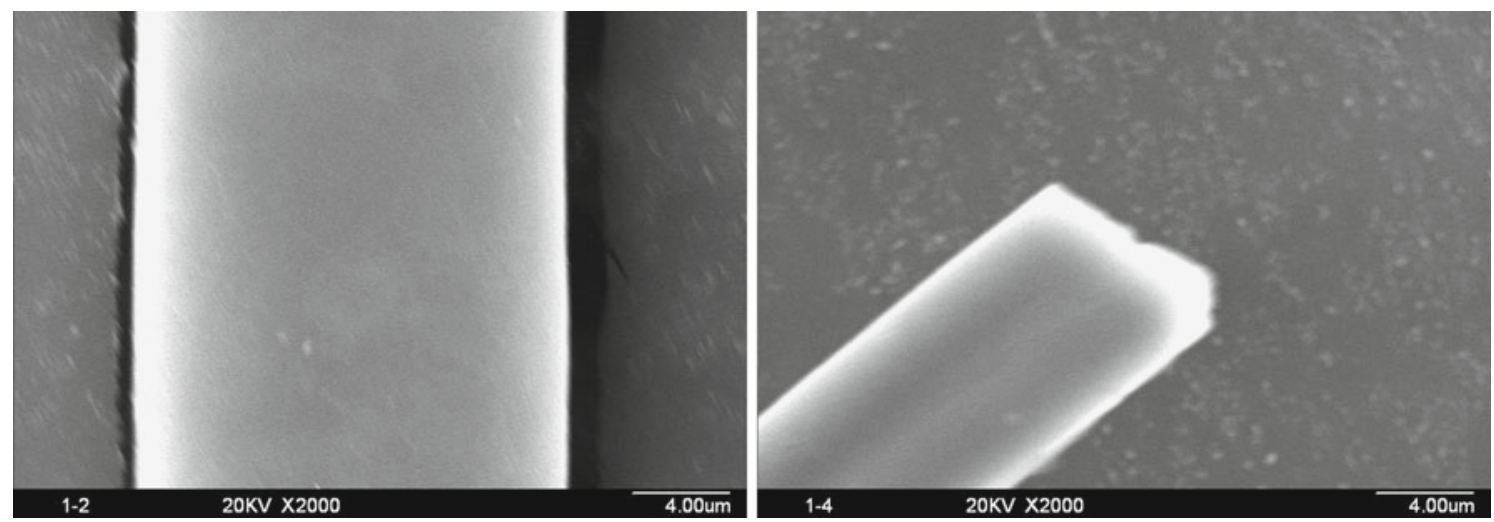

Figure 5. SEM microstructures of alumina precursor gel fibres heated at $1200^{\circ} \mathrm{C}$ for $1 \mathrm{~h}$.

and $16 \mu \mathrm{m}$, with an uniform diameter. The diameter of fibres is influenced by viscosity and surface tension of the spinning sol, speed of hand drawing, and so on. Further research need to be performed to define well these correlations.

\section{Conclusions}

Continuous alumina gel fibres were prepared by sol-gel method when the spinning sol was prepared by mixing aluminum nitrate, lactic acid and polyvinylpyrrolidone with a mixed ratio of 10:3:1.5. The main phases are amorphous and $\gamma-\mathrm{Al}_{2} \mathrm{O}_{3}$ phase in the gel fibres sintered at $800{ }^{\circ} \mathrm{C}$. The gel fibres completely transformed to $\alpha-\mathrm{Al}_{2} \mathrm{O}_{3}$ fibres by sintering at $1200{ }^{\circ} \mathrm{C}$, the alumina fibres with an uniform diameter.

\section{Acknowledgements}

This work was supported by the Shaanxi Natural Science Foundation of China (No. 2012JQ6017), and the Shaanxi University of Technology Foundation of China (SLGQD1101).

\section{References}

Apelblat A, Manzurola E, Krieken J and Nanninga G L 2005 Fluid Phase Equilibr. 236162
Chandradass J and Balasubramanian M 2006 J. Mater. Process. Technol. 173275

Leivo J, Lindén M, Ritola M, Vippola M, Levanen E T and Mantyla A 2009 Mater. Chem. Phys. 11556

Li J and Sun X 2000 Acta Mater. 483103

Li J, Pan Y, Xiang C, Ge Q and Guo J 2006 Ceram. Int. 32587

Maneeratana V and Sigmund W M 2008 Chem. Eng. J. 137137

Minnesota Mining and Manufacturing Company, non-frangible alumina-silica fibres 1977 United States Patent: 4047965

Nordahl C S and Messing G L 1998 Thermochim. Acta 318187

Nordahl C S and Messing G L 2002 J. Eur. Ceram. Soc. 22415

Padmaj P, Anilkumar G M, Mukundan P, Aruldhas G and Warrier K G K 2001 Int. J. Inorg. Mater. 3693

Poulon-Quintin A, Berger M H and Bunsell A R 2004 J. Eur. Ceram. Soc. 242769

Sedaghat A, Taheri-Nassaj E and Naghizadeh R 2006 J. Non-Cryst. Solids 3522818

Shojaie-Bahaabad M, Taheri-Nassaj E and Naghizadeh R 2008 Ceram. Internat. 341893

Venkatesh R and Ramanan S R 2000 J. Eur. Ceram. Soc. 202543

Venkatesh R and Ramanan S R 2002 Mater. Lett. 55189

Zhang L and Eckert H 2004 Solid State Nucl. Mag. Resonance 26132

Zhang L, Araujo C C and Eckert H 2007 J. Non-Cryst. Solids 3531255

Zhang Y, Ding Y, Gao J and Yang J 2009 J. Eur. Ceram. Soc. 291101

Zhu L, Huang Q and Liu W 2008 Ceram. Int. 341729 